\title{
Social personality trait and fitness
}

\author{
J. Cote ${ }^{1,2, *}$, A. Dreiss ${ }^{1,3}$ and J. Clobert ${ }^{1,4}$
}

${ }^{1}$ Laboratoire Fonctionnement et Evolution des Systèmes Ecologiques, Université Pierre et Marie Curie, 75252 Paris Cedex 05, France

${ }^{2}$ Department of Environmental Science and Policy, University of California, Davis, CA 95616, USA

${ }^{3}$ Department of Ecology and Evolution, University of Lausanne, 1015 Lausanne, Switzerland

${ }^{4}$ Station d'Ecologie Expérimentale du CNRS à Moulis, Laboratoire Evolution et Diversité Biologique, Moulis, 09200 Saint-Girons, France

\begin{abstract}
Several recent studies have explored various aspects of animal personality and their ecological consequences. However, the processes responsible for the maintenance of personality variability within a population are still largely unknown. We have recently demonstrated that social personality traits exist in the common lizard (Lacerta vivipara) and that the variation in sociability provides an explanation for variable dispersal responses within a given species. However, we need to know the fitness consequences of variation in sociability across environmental contexts in order to better understand the maintenance of such variation. In order to achieve this, we investigated the relationship between sociability and survival, body growth and fecundity, in one-year-old individuals in semi-natural populations with varying density. 'Asocial' and 'social' lizards displayed different fitness outcomes in populations of different densities. Asocial lizards survived better in low-density populations, while social females reproduced better. Spatiotemporal variation in environmental conditions might thus be the process underlying the maintenance of these personality traits within a population. Finally, we also discuss the position of sociability in a more general individual behavioural pattern including boldness, exploration and aggressiveness.
\end{abstract}

Keywords: sociability; survival; growth rate; reproduction; behavioural syndromes; common lizard

\section{INTRODUCTION}

Consistent individual differences across time and contexts have been observed in numerous behavioural patterns (e.g. Gosling 2001; Dall et al. 2004; Sih et al. 2004; Bell $2007 b$ ). These differences have revealed themselves in exploration, aggressiveness, reactivity, boldness and social tolerance in both vertebrates and invertebrates (Dall et al. 2004; Sih et al. 2004; Bell 2007a; Réale et al. 2007) and are analogous to personality traits in humans. Although numerous studies have explored personality traits, the processes responsible for the maintenance of personality variation within a population are still mostly unknown (Dall et al. 2004; Sih et al. 2004; Dingemanse \& Réale 2005; Bell 2007a; Stamps 2007). Several scenarios have been proposed such as frequency-dependent selection and spatiotemporal variation in environmental conditions (Dall et al. 2004; Smith \& Blumstein 2008). Recent studies have suggested that trade-offs between life-history traits may favour the evolution and the maintenance of personalities (McElreath et al. 2007; Stamps 2007; Wolf et al. 2007). For instance, Stamps (2007) suggested that growth-mortality trade-offs might explain the maintenance of personality traits in a predation context. Indeed, a given personality might positively affect some life-history traits to the detriment of other life-history traits, yielding equal fitness for each personality and maintaining the diversity of personalities within a population. Disentangling these processes requires a measure of the fitness

\footnotetext{
* Author and address for correspondence: Department of Environmental Science and Policy, University of California, Davis, CA 95616, USA (jdcote@ucdavis.edu).
}

consequences of personality traits (Dingemanse \& Réale 2005). A few studies have indeed reported that personality traits relate to some fitness components, such as survival and reproduction (Réale \& Festa-Bianchet 2003; Dingemanse et al. 2004; Both et al. 2005; Dingemanse \& Réale 2005; Boon et al. 2007) and argued that fluctuating selection related to temporal environmental heterogeneity could be the factor that explains the maintenance of different personality types. Spatial variation in environmental conditions also might explain the maintenance of variability in personality types. Indeed, individuals with different personality traits display different dispersal behaviours (Fraser et al. 2001; Dingemanse et al. 2003; Cote \& Clobert 2007; Duckworth \& Badyaev 2007). It might well be that spatial variation in the environment selects for variation in personality traits among residents and dispersers. Experimental studies may help to assess the personality-fitness links along varying ecological conditions, thus furthering the understanding of the maintenance of personality variation.

In this study, we investigated the relationship between sociability and some fitness components in varying social contexts. Sociability is a poorly studied personality trait that is believed, however, to strongly affect population dynamics (Cote \& Clobert 2007; Réale et al. 2007). In the common lizard (Lacerta vivipara), individuals are found to vary in the degree of their social tolerance (i.e. sociability). This behavioural trait is constant throughout an individual's lifetime and independent of the social context in which it is observed (Cote \& Clobert 2007). Dispersal behaviour was also related to individual sociability levels in the interaction with population density. Together these 
results suggest that some juveniles leave their natal population in search of more socially attractive or dense populations, while other juveniles disperse in order to avoid crowded populations. This variation in sociability provides an explanation for the existence of positive and negative density-dependant dispersal responses within a given species (Cote \& Clobert 2007). However, the benefits of this sociability-dependent dispersal are still unknown and the fitness consequences of varying sociability levels across environmental contexts require further study. The common lizard is characterized by a meta-population system with strong variations in population densities occurring naturally among connected populations (Massot et al. 1992; Clobert et al. 1994). This species is therefore suitable for the testing of the relationship between sociability and fitness in varying social contexts. To achieve this goal, we experimentally measured the attraction of individuals towards the odour of conspecifics at birth, a metric of sociability. We then released individuals of known sociability as juveniles into experimental populations of different densities and measured the subsequent survival, body growth and fecundity of one-year-old individuals. It allowed us to test for the interaction between sociability and population density on fitness - the condition for the maintenance of variability in the social personality trait through spatial environmental variations. We predict that fitness is positively related to social tolerance in highdensity populations, whereas the opposite pattern is expected in low-density populations. It has previously been suggested that sociability might be part of a more general behavioural pattern, adding a social aspect to other personality traits such as boldness, aggressiveness and exploration (Cote \& Clobert 2007; Réale et al. 2007). Therefore, we also explored the relationships between social tolerance at birth and a boldness index.

\section{MATERIAL AND METHODS}

\section{(a) Species}

The common lizard is a small member of the Lacertidae (adult snout-vent length: males $40-60 \mathrm{~mm}$, females $45-75 \mathrm{~mm}$ ) that inhabits humid habitats across Eurasia (Avery 1962). Lizards become active from late March to the beginning of April (Massot et al. 1992) and start hibernating in late September. Males emerge from hibernation in February-March, approximately two weeks earlier than subadults and one month earlier than females. Immediately after the females' emergence, copulation can be observed. During mating attempts, a male grips the female on the posterior abdomen with its mouth, and then tries to twist its body around the female, in order to introduce its hemipenis into the female's cloacae. Female common lizards show a short receptive window during which they mate with several different partners (Heulin 1988; Lecomte et al. 1994). In our semi-natural populations, some females start reproducing at the age of 1 year, while all other females reach maturity at the age of 2 years (Lecomte et al. 2004). Females produce offspring once a year and egg-laying occurs in June-July, in our semi-natural conditions. Juveniles are independent of their mother immediately after birth.

\section{(b) Study site and rearing conditions}

This experiment was conducted using lizards living in seminatural populations at the Ecological Research Station of Foljuif (Seine-et-Marne, $48^{\circ} 17^{\prime} \mathrm{N}, 2^{\circ} 41^{\prime} \mathrm{E}$, Le Galliard et al. 2003a) for a period of 3 years. Populations of the common lizard are kept in enclosures $(10 \times 10 \mathrm{~m})$ protected from avian and mammalian predation. The enclosure size is equivalent to the individual's core home range size observed in natural populations (Boudjemadi et al. 1999a) and lizards feed on the food occurring naturally in the enclosure.

In June 2004, we captured 96 adult males and 176 adult females from the stocking enclosures. The males were released a few days after the capture (see below for the experimental protocol-except for the non-experimental males used for social tolerance measurement-see below), whereas the females were kept in the laboratory until they gave birth. In order to provide each lizard with the same standardized environment (e.g. food, water, heat, social interactions), pregnant females were individually housed in plastic terrariums $(25 \times 15.5 \times 15 \mathrm{~cm}$, containing a $3 \mathrm{~cm}$ litter; Le Galliard et al. 2003a). In one corner of the terrarium, a bulb provided heat for thermoregulation and light from 09.00 to 12.00 , and from 13.00 to 17.00 . A piece of cardboard and a plastic tube were provided to allow the lizards to hide. The female lizards gave birth in the terrariums and all offspring were thereafter released into semi-natural populations as described below in $\S 4 d$. On the day of birth, all dead and viable offspring were measured for body length (nearest $\mathrm{mm}$ ), tail length (nearest $\mathrm{mm}$ ) and body mass (nearest $\mathrm{mg}$ ), and their sex was determined by counting ventral scales (Lecomte et al. 1992). Juveniles were individually marked by toe-clipping, in order to facilitate identification at a later date.

\section{(c) Test for social tolerance}

Social tolerance was measured as described in Cote \& Clobert (2007). Adult males were selected as the odour donors (see Cote \& Clobert (2007) for further explanations). To obtain olfactory cues, six different pairs of adult males were maintained in the same terrarium for the whole laying period. We collected odours on a piece of absorbent paper placed on the floor of the terrarium for 6 days. We also maintained six uninhabited terrariums under the same conditions as in the inhabited terrariums (i.e. light, heat and humidity). This method allows us to obtain pieces of paper differing only with respect to the presence of olfactory cues. We used each piece of paper only once. This technique has been successfully used in other contexts and proved to induce natural behaviours in the field (de Fraipont et al. 2000; Léna et al. 2000; Aragón et al. 2006).

We tested 208 neonates for social tolerance the day after their birth. Behavioural measurements were performed in plastic terrariums of the same dimensions as the maternal terrariums. A piece of egg-carton (shelter) was added to the centre of the terrarium allowing the lizards to hide and a bulb was provided heat for thermoregulation. Each lizard was tested separately in a cleaned terrarium, beginning alternatively with the odorized paper, or with the non-odorized paper. This allows us to completely separate the effect of olfactory cues from all other potential effects of experimental procedure. We placed the odorized paper under the shelter. The lizard could choose to spend time either under the shelter with a conspecific's odour or outside the shelter and exposed. After $5 \mathrm{~min}$ of acclimation, we quantified the amount of a $10 \mathrm{~min}$ trial spent under the shelter when faced with a conspecific's odour as a metric of social tolerance. The same observer performed all the tests. Each lizard was introduced into a terrarium with the piece of absorbent paper and left for $5 \mathrm{~min}$ to 
acclimatize. Then, the time spent hidden under the shelter was measured for a $10 \mathrm{~min}$ interval. After these measurements, the piece of paper was changed, but the lizards were not moved. After $5 \mathrm{~min}$, we again measured the time spent hidden under the shelter for a $10 \mathrm{~min}$ interval. The lizard was then removed and placed in the terrarium of its mother. We reiterated the same procedure for all the offspring. When it was impossible to test all the neonates born within the same day, we randomly selected at least two juveniles per family (one male and one female) for testing. The tests done within the same day were temporally homogeneous for individual characteristics and subsequent density treatment $(p>0.2)$. Social tolerance was approximated from the difference in the time spent under the shelter in the presence of odour, minus the time spent under the shelter in the absence of odour (Cote \& Clobert 2007).

During these behavioural measurements, we also measured the time spent basking below the light (for time spent immobile above the shelter and below the light, see Carpenter \& Ferguson 1977; Cote et al. 2008). Here, our behavioural measurements reflect how neonates behaved when faced with a novel environment (i.e. terrarium, see de Fraipont et al. 2000). Time spent basking below the light and above the shelter by lizards may be seen as an index of boldness. Indeed, a trade-off between the necessity of basking and the risks of being exposed (e.g. predation) modulate a lizard's propensity to bask in natural situations ( $\mathrm{J}$. Cote 2007, unpublished data). In our experimental terrariums, the lizards have also been observed putting only their head below the light (the rest of the body remaining under the shelter) or basking next to the shelter. These low-basking behaviours are less efficient, and might reflect the trade-off between shyness and the need to bask below the light. The time spent basking exposed during the two trials (with and without odour) were positively correlated $\left(F_{1,206}=14.00\right.$, $p=0.001$ ), suggesting an individual variation in boldness. We used the mean time spent basking during the two trials (with and without odour) as a metric of boldness. Therefore, our metric of boldness is more likely to reflect the general pattern over social and non-social contexts. We decided to use the time spent basking above the shelter rather than the total amount of time spent outside for several reasons. First, a common lizard basking stays immobile above an exposed substrate (e.g. rocks) and then is completely exposed to both avian and terrestrial predators, while, in natural conditions, a lizard outside a shelter moves in a densely vegetated habitat, which reduces the risk of predation. Second, in our behavioural set up, outside lizards mainly moved all around the terrarium. This behaviour is likely to reflect a exploratory behaviour (de Fraipont et al. 2000), rather than a boldness behaviour. Including the time spent outside may confound the attempt to distinguish between boldness and exploratory behaviours. We then decided to restrict our boldness measurement to the time spent above the shelter. As this boldness index was measured during the same test unlike social tolerance, the two measurements were not independent. However, we used the mean time spent basking above the shelter over the two trials (with and without odour) as a metric of boldness, while sociability was the difference in the time spent under the shelter between the two trials (with odour minus without odour). To avoid the problem of independence, we controlled for the time spent out of the shelter. We modelled the time spent basking above the shelter (i.e. boldness) with the time spent out of the shelter as a covariate. The boldness values were then the residuals of this model.

\section{(d) Field study}

In June 2004, the captured individuals were released in such a way as to create 16 semi-natural populations with two density levels (eight replicates each). Population densities were either high (adults: 8 males, 12 females; yearlings: 10 males, 10 females and 34 juveniles) or low (adults: 4 males, 6 females; yearlings: 5 males, 5 females and 17 juveniles). All 16 populations had age and sex structures similar to those of natural populations (Massot et al. 1992) and individual characteristics (i.e. body size, body mass and date of birth for juveniles) and social tolerance did not differ significantly between levels of density treatment ( $p>0.5$ for all). The males and all the yearlings were released 7 days after their initial capture, whereas the juveniles and their mothers were released 2 days after laying (see Cote \& Clobert (2007) for further explanations). The difference between density treatments (high versus low) was maintained throughout the release period by careful assignment of the juveniles and their mothers to particular enclosures. Among the juveniles tested for social tolerance, 145 were released in high-density populations and 63 in low-density populations. Furthermore, a small part of the tip of the tail of each female, male and hatchling was collected for DNA extraction. The other lizards had not been tested for social tolerance and were therefore not included in this analysis.

In our experimental populations, natal dispersal was monitored on a daily basis after release. The connection between the two populations by means of corridors served as the experimental device. The dispersers were released in another population the same day according to the procedure described in Cote \& Clobert (2007). Population density after dispersal formed the raw data for our analyses. Dispersal occurs in a short period after birth and then only population density after dispersal can affect subsequent survival and a fortiori reproductive success the following year. Furthermore, we allowed for juvenile dispersal status in our analyses and confirmed that the effects remained unaffected.

We monitored pre- and post-hibernation lizard survival via hand recaptures. Multiple recapture sessions were organized in August 2004 on two different days. At the end of May 2005, all surviving lizards were recaptured during 10 successive sessions (same recapture efficiency as above). Given the high cumulative capture rate (98\%; Le Galliard et al. 2003b), non-captured lizards were considered dead. All the surviving lizards were measured for body length, body mass and the number of mating scars on the females' bellies was counted as an index of mating activity. Surviving females (yearlings measured for social tolerance at birth, other yearlings and adults) were housed in individual terrariums $(25 \times 15 \times 15 \mathrm{~cm})$ under standardized conditions (Le Galliard et al. 2003b). The animals taken from the two density treatments were equally distributed within the laboratory and no difference in the positioning between treatments, ages and morphological traits was observed (all $p>0.40$ ). Food was provided every four days and consisted of medium-sized cricket larvae (Acheta domestica) or mealworm larvae (Pyralis sp.). Terraria were checked daily for newborns at 09.00 and 14.00. Clutch size was defined as the sum of yellow eggs (eggs containing no visible embryo), aborted embryos, dead offspring and viable offspring. Furthermore, all offspring born were tail tipped at hatching for DNA extraction. The DNA of the offspring and all putative fathers was amplified at five microsatellite markers as described in Boudjemadi et al. (1999b), Laloi et al. (2004) and Richard et al. (2005) and the paternity of all males 
Table 1. Effects of population density and social tolerance at birth on fitness outcomes (estimates are given for high-density populations $\mathrm{D}+) .\left({ }^{\#} p<0.10,{ }^{*} p<0.05\right.$.)

\begin{tabular}{|c|c|c|c|c|c|c|}
\hline \multirow[b]{2}{*}{ factors } & \multicolumn{2}{|l|}{ survival } & \multicolumn{2}{|l|}{ body growth } & \multicolumn{2}{|l|}{ gravidity } \\
\hline & estimates \pm s.e & test statistics & estimates \pm s.e & test statistics & estimates \pm s.e & test statistics \\
\hline $\begin{array}{l}\text { density }(\mathrm{D}+) \\
\text { social tolerance } \\
\text { density } \times \text { tolerance } \\
\text { date of birth } \\
\text { body length in May }\end{array}$ & $\begin{array}{r}0.39 \pm 0.38 \\
-0.001 \pm 0.001 \\
0.003 \pm 0.001 \\
0.027 \pm 0.035\end{array}$ & $\begin{array}{l}F_{1,14}=1.01 \\
F_{1,133}=0.08 \\
F_{1,133}=4.01^{\#} \\
F_{1,132}=0.63 \\
-\end{array}$ & $\begin{array}{c}-2.04 \pm 0.98 \\
0.003 \pm 0.001 \\
-0.003 \pm 0.003 \\
-0.13 \pm 0.08 \\
-\end{array}$ & $\begin{array}{l}F_{1,13}=4.26^{*} \\
F_{1,43}=5.68^{\#} \\
F_{1,42}=1.11 \\
F_{1,43}=3.05^{*} \\
-\end{array}$ & $\begin{array}{c}-0.51 \pm 1.28 \\
0.005 \pm 0.003 \\
-0.07 \pm 0.09 \\
-0.04 \pm 0.12 \\
0.43 \pm 0.21\end{array}$ & $\begin{array}{l}\chi_{1}=0.16 \\
\chi_{1}=4.05^{\#} \\
\chi_{1}=0.85 \\
\chi_{1}=0.12 \\
\chi_{1}=5.83^{\#}\end{array}$ \\
\hline
\end{tabular}

measured for social tolerance at birth was scored unambiguously. The DNA of all individuals was amplified at 5 microsatellite markers (Lv-3-19, Lv-4-72, Lv-4- $\alpha, \mathrm{Lv}-4-\mathrm{X}$ and Lv-4-115; as described in Boudjemadi et al. (1999b) and Laloi et al. (2004)). The paternity of all males measured for social tolerance at birth was scored unambiguously by a likelihood approach using Cervus software v. 2.0 (Marshall et al. 1998). The exclusionary power ranged between 0.937 and 0.999 depending on the enclosure (Laloi et al. 2004).

\section{(e) Statistical analyses}

The first analyses explored the correlations between social tolerance at birth and other traits (boldness, body length and body condition) using the MIXED procedure in SAS v. 8.02 (Littell et al. 1996). This procedure allowed us to include family in the model as a random effect. The other analyses aimed at determining whether survival probabilities, body growth rates (body length in May 2005 minus body length at birth) and reproductive characteristics depended on the interaction between social tolerance and population density. The survival status was analysed using the GLIMMIX procedure in SAS v. 8.02 (Littell et al. 1996) with a logit link function and a binomial error term. The body growth rate was analysed using the MIXED procedure in SAS v. 8.02. The fixed effects were the density of the population, the individual sociability and boldness indexes and their interaction. We also included initial body length as a covariate. The random effects were population (nested within the density treatment) and family (nested within population). The probability of showing mating scars and the probability of being gravid for surviving females were analysed using the GENMOD procedure in SAS v. 8.02 with a logit link function and a binomial error term. The fixed effects were the density of their population, the social tolerance and the interaction.

The correlations between social tolerance, boldness and clutch characteristics (clutch size, number of viable offspring) were analysed using Spearman's rank correlations in JMP v. 5.0.1. The probability that a young male reproduced with at least one female and the number of offspring assigned to that male were analysed using the same procedure as that used for females. The assumptions of all theses models were verified on the residuals. Simplification of all models was made using backward elimination of the non-significant terms. Significance level was set at $p=0.05$.

\section{RESULTS}

\section{(a) Social tolerance at birth and other traits}

Social tolerance was not correlated with body length and body condition at birth (body length: $F_{1,147}=0.76$, $p=0.38, r^{2}=0.004$; body condition: $F_{1,146}=0.40, p=0.53$, $\left.r^{2}=0.004\right)$ and did not differ between males and females
$\left(F_{1,147}=0.02, p=0.89\right)$. Social tolerance was positively correlated with our measurement of boldness (social tolerance-boldness: $\left.F_{1,147}=10.71, p=0.0013, r^{2}=0.05\right)$.

\section{(b) Survival and body growth rate}

Juvenile survival until August 2004 (i.e. pre-hibernation survival) did not depend on social tolerance at birth (social tolerance: $F_{1,133}=0.75, p=0.39$, social tolerance $\times$ population density: $F_{1,133}=0.78, p=0.38$ ), but tended to be higher in high-density populations (population density: $\left.F_{1,14}=4.14, p=0.06\right)$.

Of the 208 juveniles released in June 2004, 60 survived until May 2005. The probability of survival did not depend on population density and social tolerance alone, but on their interaction (table 1). While the probability of survival was negatively correlated with the social tolerance measured at birth in low-density populations (estimate $-0.003 \pm 0.001, F_{1,35}=7.63, p=0.009$; figure 1 ), socially tolerant lizards slightly tended to survive better in highdensity populations (estimate $0.0010 \pm 0.0006, F_{1,94}=$ $2.84, p=0.095$; figure 1 ). The probability of survival did not depend on boldness (boldness: $F_{1,131}=0.46, p=0.50$; boldness $\times$ density: $\left.F_{1,131}=0.94, p=0.33\right)$ and the effects of social tolerance remained significant when we added boldness in the model. Finally, growth rate was not affected by boldness (boldness: $F_{1,40}=1.01, p=0.32$; boldness $\times$ density: $\left.F_{1,40}=0.08, p=0.77\right)$ but was positively correlated with social tolerances (figure 2; $\left.r^{2}=0.08\right)$ and was slightly higher in low-density populations (table 1). Date of birth also tended to negatively affect growth rate (table 1 ).

\section{(c) Reproductive success}

Although the probability that young females displayed mating scars was positively correlated with social tolerance (estimate $0.0030 \pm 0.0015, n=36, \chi_{1}=4.93, p=0.027$; figure $3 b$ ), it did not depend on population density (population density: $\chi_{1}=0.68, p=0.41$ and density $\times$ social tolerance: $\left.\chi_{1}=0.56, p=0.77\right)$. A young female's probability of being gravid was also positively correlated with its social tolerance and with its body length, but was independent of its population density (table 1 ; figure $3 a$ ). Boldness did not affect the probability of being bitten (boldness: $\chi_{1}=2.71$, $p=0.10$; boldness $\times$ density: $\left.\chi_{1}=2.36, p=0.12\right)$ and the probability of being gravid (boldness: $\chi_{1}=0.02, p=0.88$; boldness $\times$ density: $\chi_{1}=0.76, p=0.38$ ) and the effects of social tolerance remained significant when we included boldness as a covariate in the models.

Clutch size was also positively related to female social tolerance ( $\rho=0.73, p=0.04$; figure $3 c$ ) and was independent of boldness $(\rho=-0.07, p=0.86)$. Only four females 

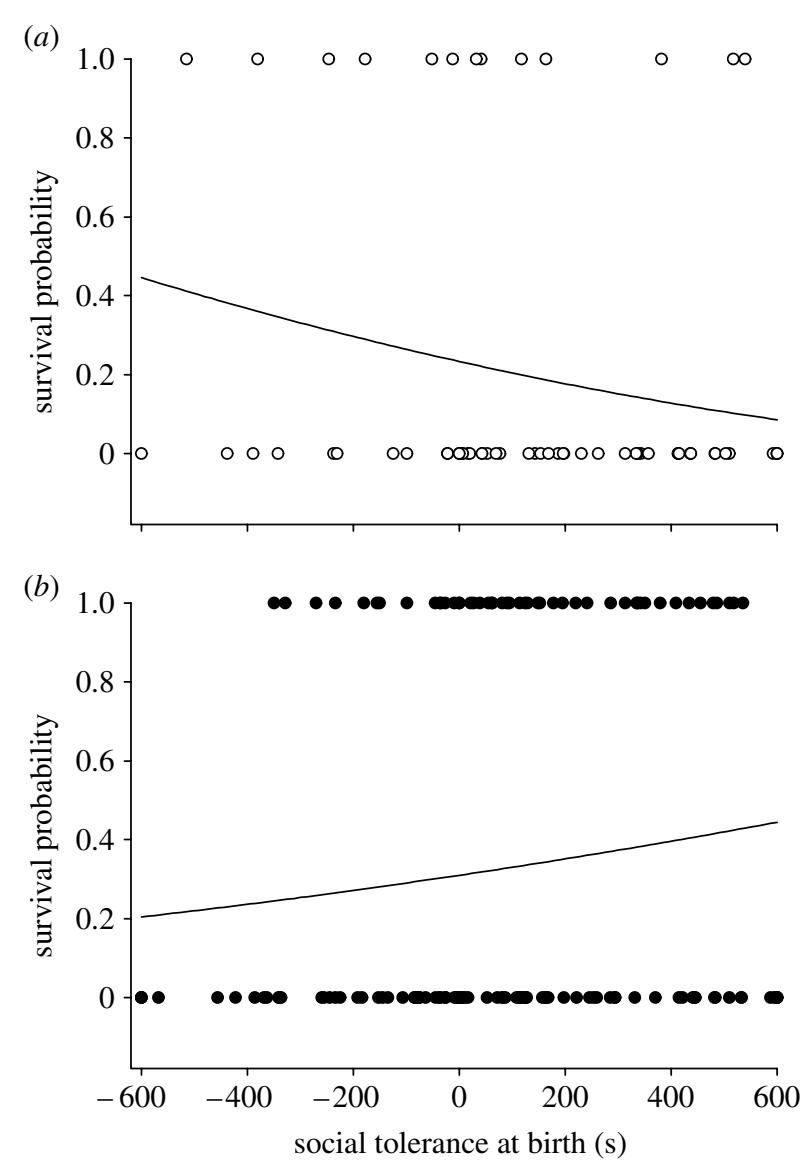

Figure 1. Sociability and density dependence of survival. Winter survival probability depending on population density and social tolerance at birth in (a) low-density populations and $(b)$ high-density populations. Each circle corresponds to individual survival status after one year. Curves have been fitted from predicted values.

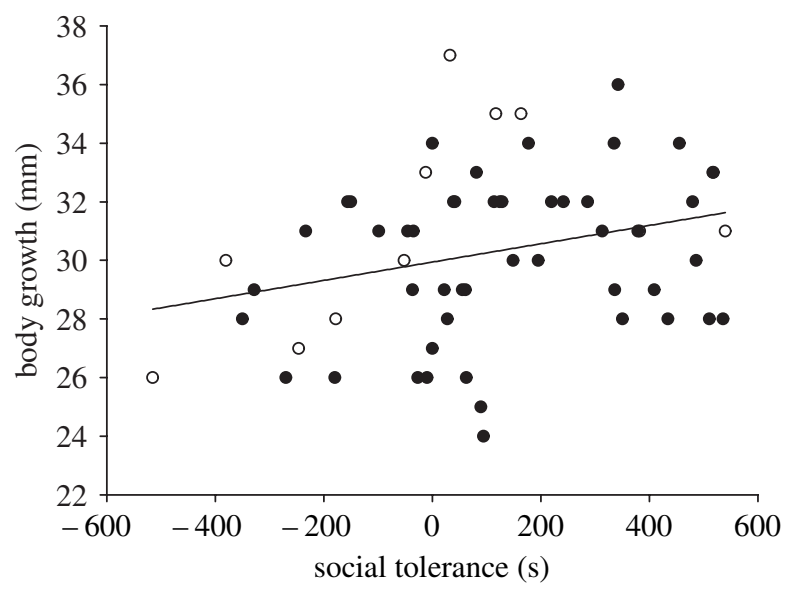

Figure 2. Sociability dependence of body growth rate. Body growth rate (body length after one year minus natal body length $(\mathrm{mm})$ ) along the gradient of social tolerance at birth. Each circle corresponds to an individual (open circle, individuals from low-density populations; closed circle, individuals from high-density populations). Regression line is shown.

produced viable offspring during this first reproduction cycle. We were able to provide an appraised test, despite the fact that the number of females was low. The number of viable offspring produced by these four gravid females was related to female social tolerance $(\rho=0.95, p=0.05$; figure $3 d$ ) and was independent of boldness $(\rho=-0.24$, $p=0.56)$. The laying date was not significantly related to female social tolerance $(\rho=0.43, p=0.29)$ or to female boldness $(\rho=-0.38, p=0.35)$.

As the males might have reproduced and died before capture in May 2005, we need to include in the analysis all the males released in June 2004. The probability that a young male reproduced with at least one female did not depend on population density, social tolerance or boldness (social tolerance: $\chi_{1}=0.08, p=0.77$; population density: $\chi_{1}=0.30, p=0.58$; density $\times$ social tolerance: $\chi_{1}=0.00, p=0.97$; boldness: $\chi_{1}=1.12, p=0.29$; boldness $\times$ density: $\left.\chi_{1}=0.25, p=0.62\right)$. The number of offspring assigned to these males was related to neither their social tolerance $(\rho=-0.12, p=0.77)$ nor boldness $(\rho=0.27, p=0.47)$.

\section{DISCUSSION}

\section{(a) Sociability and fitness outcomes}

Lizards of different social tolerances displayed different fitness outcomes in populations of low and high densities. These results support the hypothesis that spatiotemporal variation in environmental conditions may maintain the variation in personality types. Offspring survival during their first year was related to social tolerance at birth with respect to population density. In our experiment, we used the attraction of juveniles towards the odour of conspecifics at birth as a metric of social tolerance. In highdensity populations, social tolerance did not strongly affect survival. By contrast, social individuals had a lower probability of survival in low-density populations. In the common lizard, competition for space and food resources is dominated by adult males (Lecomte et al. 2004). Furthermore, adult males are strongly aggressive, especially during the mating season (i.e. post-hibernation period, Lecomte et al. 2004). Therefore, aggressive social interactions with males and male dominance for resources may constrain the growth and survival in subadults (Massot et al. 1992). For each individual, sociability/ social tolerance will affect the intensity of its social interactions, and therefore its space use. 'Asocial' individuals may avoid social interactions, and thus competition for suitable places (e.g. shelter, basking spot) and food. This avoidance should decrease the direct (bites) and indirect (anxiety, stress) effects of competition but limit resource access. Competition for resources should be less intense in low-density populations. Therefore, asocial juveniles can access resources more easily in low- than in high-density ones. Although interactions among individuals should be more infrequent in low than in high-density populations, 'social' individuals should still display more interactive behaviours with adult males in a low-density context. Adult male aggressiveness associated with a lower pay-off from competition might result in the lower survival of social individuals in low-density populations. This is one potential scenario. However, the lack of effects on prehibernation survival (i.e. until August) implies that the influence of social personalities on survival is mostly due to post-hibernation interactions with adult males. This scenario is also supported by the effects on growth rate. Social tolerance positively affected body growth rate. Indeed, survivors are individuals bearing aggressiveness and acquiring sufficient resources. Social survivors 

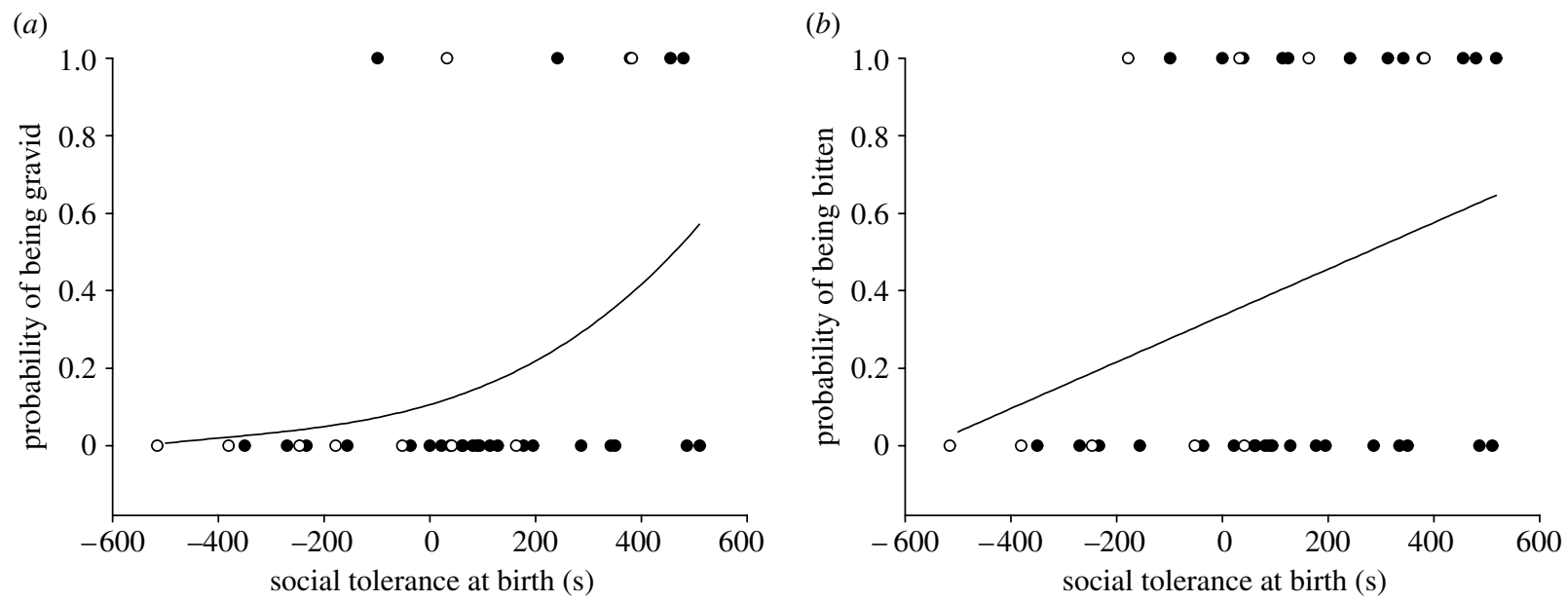

(c)

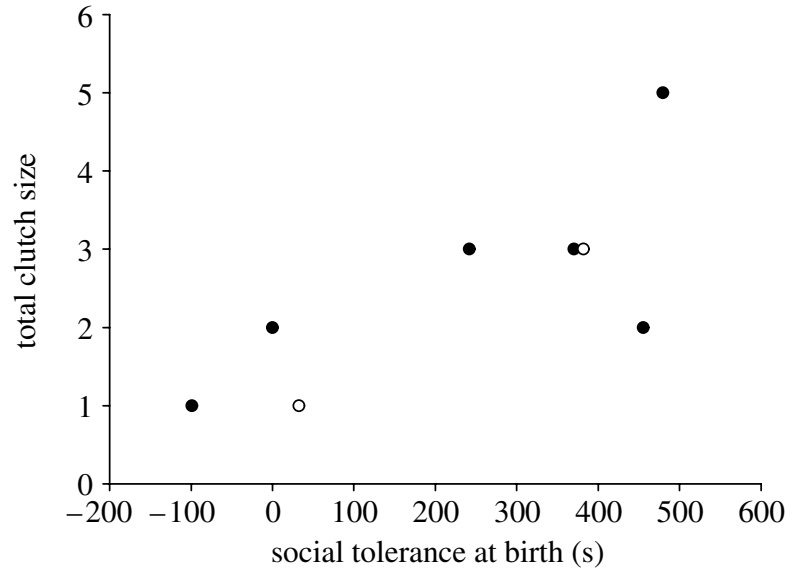

(d)

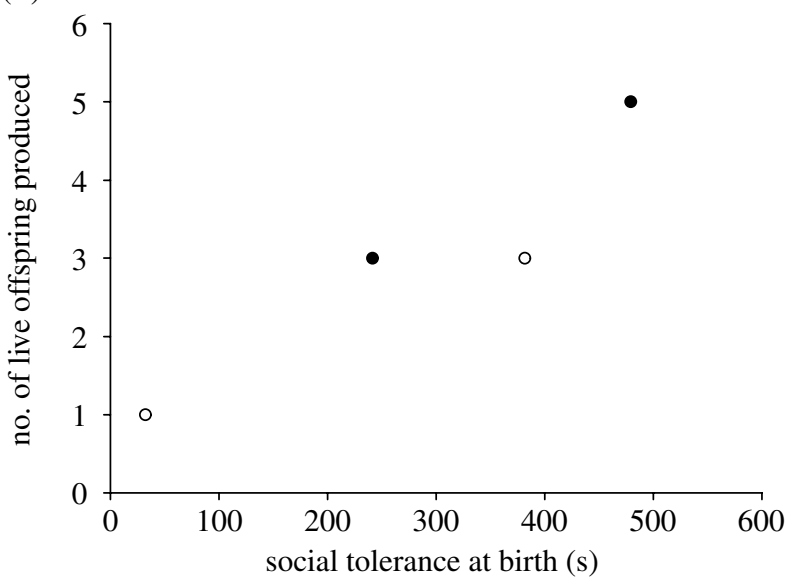

Figure 3. Sociability dependence of reproductive traits. Each circle corresponds to an individual (open circles, individuals from low-density populations; closed circles, individuals from high-density populations) along the gradient of social tolerance at birth. (a) Probability of being gravid. Curve has been fitted from predicted values. (b) Probability of being bitten. Curve has been fitted from predicted values. $(c)$ Total clutch size (sum of eggs containing no visible embryo, aborted embryos, dead offspring and viable offspring). (d) Number of live offspring produced.

should thus be better competitors, acquiring more or better resources in high-density as well as in low-density populations. Their better capacities result in a higher body growth rate.

Furthermore, social tolerance was found to influence female reproduction. Social females had a higher probability of being gravid independent of their body length. These females were also bitten more, which implied that they had been subjected to a greater number of mating attempts (Le Galliard et al. 2005). As social individuals probably used high-density areas within a population, social females should have met more males during the mating period. In this species, a successful fertilization is rare in one-year-old females. The accumulation of mating attempts might allow social females to be fertilized. Even if only a few one-year-old females reproduced, the total clutch size and the number of offspring produced seem to be positively related to social tolerance. All these results indicate an earlier and better reproduction for social females. By contrast, social tolerance did not affect the reproduction of young males. The social male yearlings did not reproduce more than the asocial ones. During the mating period, since all males actively search for females, their mating probability is unlikely to depend upon their social behaviour.

\section{(b) How variation in sociability is maintained within a population?}

Several processes have been proposed for the existence and the maintenance of variation in personality. Besides genetic and developmental backgrounds, fitness consequences of social personality trait have to be measured to disentangle these processes (Dingemanse \& Réale 2005; van Oers et al. 2005; Réale et al. 2007; Smith \& Blumstein 2008). In this species, approximately 20 per cent of juveniles survive their first year. First year survival is therefore a crucial parameter in the life cycle of this species. Social tendencies affect survival with respect to population density. Juveniles with low social tolerance at birth survived better in low-density populations and tended to survive less well in high-density populations when compared with juveniles with higher social tolerance. It follows that the effect of variation in social tolerance on first year survival is context dependent. As in other species (Réale \& Festa-Bianchet 2003; Dingemanse et al. 2004; Boon et al. 2007), spatiotemporal variation in environmental conditions might constitute the most parsimonious explanation for the maintenance of variation in personality in common lizards as well. Indeed, the common lizard lives in densely vegetated and heterogeneous habitats (Avery 1962). In natural conditions, the 
density of conspecifics varies strongly within a population (Clobert et al. 1994). Social and asocial juveniles might thus choose micro-habitats based on the number of potential neighbours. Moreover, population density varies from year to year. Altogether, these results suggest that spatiotemporal variation in environmental conditions allows the maintenance of a social personality trait in this species.

It is interesting to note that reproduction of one-year-old females is positively related to social tolerance irrespective of population density. This might be an important benefit for social females. Nevertheless, three other results moderate this benefit. First, male reproductive success did not depend on social tolerance. Therefore, males do not necessarily benefit from being social. Second, a low proportion of females start reproducing at the age of 1 year, while all remaining females reach maturity at the age of 2 years. The higher reproductive success of more socially tolerant one-year-old females might be explained by a higher sexual harassment, which in turn might incur a cost, at present still unknown, on long-term survival or future reproductive success (Le Galliard et al. 2005). To fully conclude, we will need to perform experiments on long-term fitness consequences of social tendencies.

\section{(c) The significance of social tolerance}

The reaction towards the odour of conspecifics can be related to multiple phenotypic traits. The interpretation of our results depends crucially on disentangling these traits. We have previously suggested that social personality might be part of a more general individual behavioural syndrome, introducing a social aspect to other personality traits such as boldness, aggressiveness and exploration (Cote \& Clobert 2007). Indeed, we found that social tolerance was positively correlated with the boldness index. Allowing for the fact that our measurement of boldness is relatively simple, our results indicate that sociability is an important trait of behavioural syndromes, including boldness, aggressiveness and exploration, which might have fitness consequences in fluctuating environments. As the asocial lizards seemed to be also shyer individuals, our results could as well reflect the influence of other personality traits on fitness components. We found that boldness did not influence observed life-history traits (contrary to social tolerance). This might be explained by the absence of predation in our system (see also Clobert et al. 2000). Indeed, variation in boldness is believed to arise in a predation context (Bell \& Sih 2007; Stamps 2007). In absence of predation, the costs and the benefits of boldness are likely to disappear. However, variation in sociability still affects fitness components in the absence of predation. This suggests that the observed fitness modifications should be at least partly explained by sociability itself and that sociability should influence fitness components in a more general context.

\section{CONCLUSION}

In the common lizard, social tolerance is consistent through time and situation. This social tendency, component of a more general behavioural syndrome, affects the fitness of subadults with respect to social context. Our results also support the hypothesis that spatiotemporal variation in environmental conditions is one of the processes underlying the maintenance of different personality types within populations. We therefore suggest that variation in sociability may strongly affect population dynamics and should not be neglected in future studies on behavioural syndromes and the effects of personality on population viability.

The authors attest to the adherence of the National Institute of Health Guide for Care and Use of Laboratory Animals.

The authors are grateful to Kees van Oers, Sean Fogarty, and two referees for their comments on the present article. Claire Lamotte, Simon Boudsocq and Laurent Carlier kindly assisted during the experiment. The authors acknowledge the Ecole Normale Supérieure for technical support at the Biological Station of Foljuif. The work was financially supported by the Observatoire de Recherche en Environnement Nr. 53 of the Ministère de la Recherche française, and the programme ANR DIAME.

\section{REFERENCES}

Aragón, P., Massot, M., Gasparini, J. \& Clobert, J. 2006 Socially acquired information from chemical cues in the common lizard, Lacerta vivipara. Anim. Behav. 72, 965-974. (doi:10.1016/j.anbehav.2005.11.023)

Avery, R. A. 1962 Notes on the biology of Lacerta vivipara L. Br. F. Herpetol. 3, 165-170.

Bell, A. M. 2007a Future directions in behavioural syndromes research. Proc. R. Soc. B 274, 755-761. (doi:10. 1098/rspb.2006.0199)

Bell, A. M. $2007 b$ Evolutionary biology: animal personalities. Nature 447, 539-540. (doi:10.1038/447539a)

Bell, A. M. \& Sih, A. 2007 Exposure to predation generates personality in threespined sticklebacks (Gasterosteus aculeatus). Ecol. Lett. 10, 828-834. (doi:10.1111/j.14610248.2007.01081.x)

Boon, A. K., Reale, D. \& Boutin, S. 2007 The interaction between personality, offspring fitness and food abundance in North American red squirrels. Ecol. Lett. 10, 1094-1104. (doi:10.1111/j.1461-0248.2007.01106.x)

Both, C., Dingemanse, N. J., Drent, P. J. \& Tinbergen, J. M. 2005 Pairs of extreme avian personalities have highest reproductive success. F. Anim. Ecol. 74, 667-674. (doi:10. 1111/j.1365-2656.2005.00962.x)

Boudjemadi, K., Lecomte, J. \& Clobert, J. 1999 a Influence of connectivity on demography and dispersal in two contrasting habitats: an experimental approach. F. Anim. Ecol. 68, 1207-1224. (doi:10.1046/j.1365-2656.1999.00363.x)

Boudjemadi, K., Martin, O., Simon, J. C. \& Estoup, A. 19996 Development and cross-species comparison of microsatellite markers in two lizard species, Lacerta vivipara and Podarcis muralis. Mol. Ecol. 8, 518-520.

Carpenter, C. C. \& Ferguson, G. W. 1977 Variation and evolution of stereotyped behavior in reptiles. In Biology of the Reptilia: ecology and behavior, vol. 7 (ed. C. G. D. W. Tinkle), pp. 335-554. New York, NY: Academic Press.

Clobert, J., Massot, M., Lecomte, J. \& Sorci, G. 1994 Determinants of dispersal behavior: the common lizard as a case of study. In Lizard ecology: the third generation (eds J. Vitt \& E. R. Pianka), pp. 183-206. Princeton, NJ: Princeton University Press.

Clobert, J., Oppliger, A., Sorci, G., Ernande, B., Swallow, J. G. \& Garland, T. J. 2000 Trade-offs in phenotypic traits: endurance at birth, growth, survival, predation and susceptibility to parasitism in a lizard, Lacerta vivipara. Funct. Ecol. 14, 675-684. (doi:10.1046/j.1365-2435. 2000.00477.x) 
Cote, J. \& Clobert, J. 2007 Social personalities influence natal dispersal in a lizard. Proc. R. Soc. B 274, 383-390. (doi:10. 1098/rspb.2006.3734)

Cote, J., Boudsocq, S. \& Clobert, J. 2008 Density, social information, and space use in the common lizard (Lacerta vivipara). Behav. Ecol. 19, 163-168. (doi:10.1093/beheco/ arm 119)

Dall, S. R. X., Houston, A. I. \& McNamara, J. 2004 The behavioural ecology of personality: consistent individual differences from an adaptive perspective. Ecol. Lett. 7, 734-739. (doi:10.1111/j.1461-0248.2004.00618.x)

de Fraipont, M., Clobert, J., John-Adler, H. \& Meylan, S. 2000 Increased pre-natal maternal corticosterone promotes philopatry of offspring in common lizards Lacerta vivipara. F. Anim. Ecol. 69, 404-413. (doi:10.1046/j.13652656.2000.00405.x)

Dingemanse, N. J. \& Réale, D. 2005 Natural selection and animal personality. Behaviour 142, 1159-1184. (doi:10. 1163/156853905774539445)

Dingemanse, N. J., Both, C., van Noordwijk, A. J., Rutten, A. L. \& Drent, P. J. 2003 Natal dispersal and personalities in great tits (Parus major). Proc. R. Soc. B 270, 741-747. (doi:10.1098/rspb.2002.2300)

Dingemanse, N. J., Both, C., Drent, P. J. \& Tinbergen, J. M. 2004 Fitness consequences of avian personalities in a fluctuating environment. Proc. R. Soc. B 271, 847-852. (doi:10.1098/rspb.2004.2680)

Duckworth, R. A. \& Badyaev, A. V. 2007 Coupling of dispersal and aggression facilitates the rapid range expansion of a passerine bird. Proc. Natl Acad. Sci. USA 104, 15 017-15 022. (doi:10.1073/pnas.0706174104)

Fraser, D. F., Gilliam, J. F., Daley, M. J., Le, A. N. \& Skalski, G. T. 2001 Explaining leptokurtic movement distributions: intrapopulation variation in boldness and exploration. Am. Nat. 158, 124-135. (doi:10.1086/321307)

Gosling, S. D. 2001 From mice to men: what can we learn about personality from animal research? Psychol. Bull. 127, 45-86. (doi:10.1037/0033-2909.127.1.45)

Heulin, B. 1988 Observations sur l'organisation de la reproduction et sur les comportements sexuels et agonistiques chez Lacerta vivipara. Vie Milieu 38, 177-187.

Laloi, D., Richard, M., Lecomte, J., Massot, M. \& Clobert, J. 2004 Multiple paternity in clutches of common lizard Lacerta vivipara: data from microsatellite markers. Mol. Ecol. 13, 719-723. (doi:10.1046/j.1365-294X.2004. 02102.x)

Lecomte, J., Clobert, J. \& Massot, M. 1992 Sex identification in juveniles of Lacerta vivipara. Amphib. Reptil. 13, 21-25. (doi:10.1163/156853892X00193)

Lecomte, J., Clobert, J., Massot, M. \& Barbault, R. 1994 Spatial and behavioural consequences of a density manipulation in the common lizard. Ecoscience 1, 300-310.

Lecomte, J., Boudjemadi, K., Sarrazin, F., Cally, K. \& Clobert, J. 2004 Connectivity and homogenisation of population sizes: an experimental approach in Lacerta vivipara. F. Anim. Ecol. 73, 179-189. (doi:10.1111/j.13652656.2004.00796.x)
Le Galliard, J.-F., Ferrière, R. \& Clobert, J. 2003a Motheroffspring interactions affect natal dispersal in a lizard. Proc. R. Soc. B 270, 1163-1169. (doi:10.1098/rspb.2003.2360)

Le Galliard, J.-F., Le Bris, M. \& Clobert, J. $2003 b$ Timing of locomotor impairment and shift in thermal preferences during gravidity in a viviparous lizard. Funct. Ecol. 17, 877-885. (doi:10.1046/j.0269-8463.2003.00800.x)

Le Galliard, J.-F., Fitze, P. S., Ferriere, R. \& Clobert, J. 2005 Sex ratio bias, male aggression, and population collapse in lizards. Proc. Natl Acad. Sci. USA 102, 18 231-18 236. (doi:10.1073/pnas.0505172102)

Léna, J., de Fraipont, M. \& Clobert, J. 2000 Affinity towards maternal odour and offspring dispersal in the common lizard. Ecol. Lett. 3, 300-308. (doi:10.1046/j.1461-0248. 2000.00155.x)

Littell, R. C., Miliken, G. A., Stroup, W. W. \& Wolfinger, R. D. 1996 SAS system for mixed models. Cary, NC: SAS Institute, Inc.

Marshall, T. C., Slate, J., Kruuk, L. E. B. \& Pemberton, J. M. 1998 Statistical confidence for likelihood-based paternity inference in natural populations. Mol. Ecol. 7, 639-655. (doi:10.1046/j.1365-294x.1998.00374.x)

Massot, M., Clobert, J., Pilorge, T., Lecomte, J. \& Barbault, R. 1992 Density dependence in the common lizard: demographic consequences of a density manipulation. Ecology 73, 1742-1756. (doi:10.2307/1940026)

McElreath, R., Luttbeg, B., Fogarty, S. P., Brodin, T. \& Sih, A. 2007 Evolution of animal personalities. Nature 450, E5. (doi:10.1038/nature06326)

Réale, D. \& Festa-Bianchet, M. 2003 Predator-induced natural selection on temperament in bighorn ewes. Anim. Behav. 65, 463-470. (doi:10.1006/anbe.2003.2100)

Réale, D., Reader, S. M., Sol, D., McDougall, P. T. \& Dingemanse, N. J. 2007 Integrating animal temperament within ecology and evolution. Biol. Rev. 82, 291-318. (doi:10.1111/j.1469-185X.2007.00010.x)

Richard, M., Lecomte, J., De Fraipont, M. \& Clobert, J. 2005 Age-specific mating strategies and reproductive senescence. Mol. Ecol. 14, 3147-3155. (doi:10.1111/j.1365294X.2005.02662.x)

Sih, A., Bell, A. \& Johnson, J. C. 2004 Behavioral syndromes: an ecological and evolutionary overview. Trends Ecol. Evol. 19, 372-377. (doi:10.1016/j.tree.2004.04.009)

Smith, B. R. \& Blumstein, D. T. 2008 Fitness consequences of personality: a meta-analysis. Behav. Ecol. 19, 448-455. (doi:10.1093/beheco/arm144)

Stamps, J. A. 2007 Growth-mortality tradeoffs and 'personality traits' in animals. Ecol. Lett. 10, 355-363. (doi:10. 1111/j.1461-0248.2007.01034.x)

van Oers, K., de Jong, G., van Noordwijk, A. J., Kempenaers, B. \& Drent, P. J. 2005 Contribution of genetics to the study of animal personalities: a review of case studies. Behaviour 142, 1185-1206. (doi:10.1163/156853905774539364)

Wolf, M., van Doorn, G. S., Leimar, O. \& Weissing, F. J. 2007 Life-history trade-offs favour the evolution of animal personalities. Nature 447, 581-584. (doi:10.1038/nature 05835) 